\title{
Water-Cycle-Algorithm-Tuned Intelligent Fuzzy Controller for Stability of Multi-Area Multi-Fuel Power System with Time Delays
}

\author{
CH. Naga Sai Kalyan ${ }^{1}\left(\mathbb{D}\right.$, B. Srikanth Goud ${ }^{2} \mathbb{D}$, Mohit Bajaj ${ }^{3} \mathbb{D}$, Malligunta Kiran Kumar ${ }^{4}$, Emad M. Ahmed ${ }^{5, *}$ (D) \\ and Salah Kamel ${ }^{6}$ (D)
}

check for updates

Citation: Kalyan, C.N.S.; Goud, B.S.; Bajaj, M.; Kumar, M.K.; Ahmed, E.M.; Kamel, S. Water-Cycle-AlgorithmTuned Intelligent Fuzzy Controller for Stability of Multi-Area Multi-Fuel Power System with Time Delays. Mathematics 2022, 10, 508. https:// doi.org/10.3390/math10030508

Academic Editor: Adrian Olaru

Received: 15 December 2021

Accepted: 2 February 2022

Published: 5 February 2022

Publisher's Note: MDPI stays neutral with regard to jurisdictional claims in published maps and institutional affiliations.

Copyright: (C) 2022 by the authors. Licensee MDPI, Basel, Switzerland. This article is an open access article distributed under the terms and conditions of the Creative Commons Attribution (CC BY) license (https:// creativecommons.org/licenses/by/ $4.0 /)$.
1 Department of Electrical and Electronics Engineering, Vasireddy Venkatadri Institute of Technology, Guntur 522508, India; kalyanchallapalli@gmail.com

2 Department of Electrical and Electronics Engineering, Anurag College of Engineering, Ghatkesar 501301, India; srikanth.b@anuraghyd.ac.in

3 Department of Electrical and Electronics Engineering, National Institute of Technology, New Delhi 110040, India; mohitbajaj@nitdelhi.ac.in

4 Department of Electrical and Electronics Engineering, Koneru Lakshmaiah Education Foundation, Guntur 522502, India; kiran.malligunta@gmail.com

5 Department of Electrical Engineering, College of Engineering, Jouf University, Sakaka 72388, Saudi Arabia

6 Electrical Engineering Department, Faculty of Engineering, Aswan University, Aswan 81542, Egypt; skamel@aswu.edu.eg

* Correspondence: emamahmoud@ju.edu.sa

\begin{abstract}
In this paper, a fuzzy (F) proportional (P)-integral (I)-derivative (D) (PID) (FPID) controller optimized with a water cycle algorithm is proposed for load frequency control of a multi-area multifuel (MAMF) power system. The MAMF system has the realistic feature of communication time delays (CTDs), in order to conduct an analysis nearer to realistic practice. Initially, the MAMF system is analyzed when subjected to a step load disturbance (SLD) of $10 \%$ on area 1 . The superiority of the fuzzy PID controller is revealed upon comparing it with PID plus double derivative (DD) (PIDD) and PID controllers. The MAMF system is investigated with and without CTDs, to demonstrate their impact on system performance. Later, an additional HVDC line is incorporated in parallel with the existing AC line for further enhancement of the system performance. Finally, the MAMF system is targeted with random loading to validate the robustness of the presented control scheme.
\end{abstract}

Keywords: FPID controller; stability analysis; frequency regulation; MAMF power system; CTDs

\section{Introduction}

In modern times, frequency regulation is the most indispensable task in power systems, due to the rapid growth in load demand, integration of several renewable conversion units, formation of microgrids, the emergence of unintentional time delays and power system intricacy. Frequency fluctuations arise because of the real power gap between demand and generation. Necessary steps must be taken to minimize the real power mismatch, in order to hold the power system frequency within the specified range. This action is governed by the load frequency controller (LFC), which plays a vital role in the automatic generation control (AGC) of the interconnected power system (IPS). The IPS comprises several areas with different generation units representing diverse generation sources that are running in synchronism and are connected through transmission lines in the form of tie lines. These lines facilitate the real power exchange between deficit and surplus generation areas. Power interchange between the control areas via tie lines should be done without violating the limits. Otherwise, the lines reach the maximum feasible thermal limit, leading to line outages and hence affecting the stability of the IPS. 
The LFC safeguards the IPS stability by regulating the system frequency and power exchange via tie lines, to prevent violation of the specified range by varying generation unit operating points. The concept of the LFC was proposed by Cohen [1] using tie-line bias control in the year 1957. Later, Elgerd and Fosha [2] introduced classical controllers as frequency regulators for the multi-area thermal system, in the year 1970. Since then, researchers have concentrated more on designing frequency regulators for the IPS, to maintain stability. A literature survey discloses the usage of different power system models comprised of thermal-thermal units, hydrothermal units and a combination of conventional and renewable-energy-based systems with and without considering the constraints of nonlinearity such as the governor dead band (GDB) and the generation rate constraint (GRC), etc. These are consolidated in [3]. Irrespective of the power system model, different classical control strategies such as PI fine-tuned using a simulated annealing (SA)/genetic algorithm (GA) [4], PI/PID [5] based on the grey wolf optimizer (GWO), PID [6] with a harmony search algorithm (HSA), PI/PID [7] using a backtracking search algorithm (BSA), imperialist competitive approach (ICA)-based [8] PI/PID, ant lion optimizer (ALO)based [9] PID with double derivative (DD) gain PIDD, PID tuned with differential evolution (DE) [10], PID using an elephant herd optimizer (EHO) [11], PID optimized with a cuckoo search algorithm (CSA) [12], firefly algorithm (FA)-based PI [13], whale optimizer (WO)based [14] PID, falcon optimization algorithm (FOA)-tuned PID/PIDD [15], PID [16] based on a grasshopper optimization approach (GOA) and other hybrid $(\mathrm{H})$ algorithms such as the artificial field (HAEFA) approach [17], HFA-pattern search (PS) method [18], DEAEFA [19] etc., are reported in the literature. However, classical regulators are not sufficient to handle power system models with the non-linearity features of GRC, GDB and time delays. Some modified classical controllers such as PID with filter (N) PIDN [20] and other fractional order (FO) FOPI-FOPD controllers [21] have been proposed by researchers using some of the newest optimization algorithms to overcome the problem stated above, but only to a certain extent.

Fuzzy logic controllers (FLCs) are proven to be more efficacious in handling IPS models, especially with non-linearity constraints. However, selecting the shape of the membership functions (MFs) and the framing of the rule-based interface engine require the utmost care; otherwise, the FLC may worsen the IPS performance. In general, selection of MFs is based on pragmatic rules, which are never optimal. Thus, various optimization methods have been implemented to select the most suitable parameters for FLCs. Hence, fuzzy-aided classical controllers are gaining momentum, especially in the power system optimization domain, compared to classical controllers alone. Different fuzzy (F)-aided classical controllers that have been reported in the recent literature, such as bacteria foraging optimization (BFO) [22]/ICA [23]/tuned FPI, DEPS-tuned [24] FPI/FPID, Type-II FPID [25] based on the GWO sine cosine approach, modified DEapproach-based FPID [26], FA-tuned FPID [27], symbiotic organism search (SOS)-based FPID [28], SOA-optimized FOFPID [29], etc., are available.

WCA is a recent meta-heuristic and population-based search method which mimics the movement of the water cycle on the Earth's surface. WCA is more efficient for solving constrained optimization problems and is more efficient compared to the other populationand stochastic-based methods explained briefly in [30]. In [25], it was observed that WCAtuned controller parameters are more robust for handling IPSs with parametric uncertainty and that they show better stability. Implementation of WCA in LFCs has not been much studied in the recent literature; moreover, its robustness and ability to maintain a balance between the phases of exploitation and exploration motivated the researchers in this study to adopt WCA for the optimal tuning of FPID for the stability of an IPS. Moreover, the MAMF system is considered with the realistic constraints of GRC and CTDs. The literature survey disclosed the articles that are available with test system models considering the non-linearity of GRC and GDB. Researchers have concentrated much less on considering CTDs with a power system model for analysis purposes. Few papers have considered and demonstrated the impact of CTDs on IPS performance, and their analysis is confined to 
regulation by traditional PID [31] controllers only. Hence, the power system model studied in this paper is considered with CTDs, and the effect of CTDs on system performance in combination with a GRC is presented under the regulation of a WCA-tuned FPID controller.

Further, an HVDC line is laid in parallel with the existing AC tie line as a territorial control strategy to enhance the dynamical behaviour of the MAMF IPS. The designed secondary regulators can withstand the fluctuations that arise in the system only to a certain extent. During large load disturbances, secondary regulators alone would not be able to restore system stability. Thus, territorial control schemes are necessary to prevent system instability during time-intensive load variations. The presented AC/DC lines of the territory strategy facilitate the bulk power transfer capability among control areas whenever required; therefore, the demand in the deficit generation control area is met quickly from surplus generation areas.

Considering the above discussion, this work makes the following contributions:

a. An LFC for a MAMF IPS depicted in Figure 1 is developed in MATLAB/Simulink version R2016a.

b. A WCA-based FPID is presented as a frequency regulator whose efficacy is revealed compared to conventional PIDD/PID controllers.

c. System non-linearity constraints of GRC and CTDs are considered, to conduct research that is close to realistic practice.

d. The effect of CTDs on the MAMF IPS performance is visualized and justified.

e. The territorial control strategy of AC/DC lines is employed to further enhance the MAMF system dynamical behaviour.

f. The robustness of the presented control schemes is validated by subjecting the MAMF system to a wide range of load fluctuations in both areas.

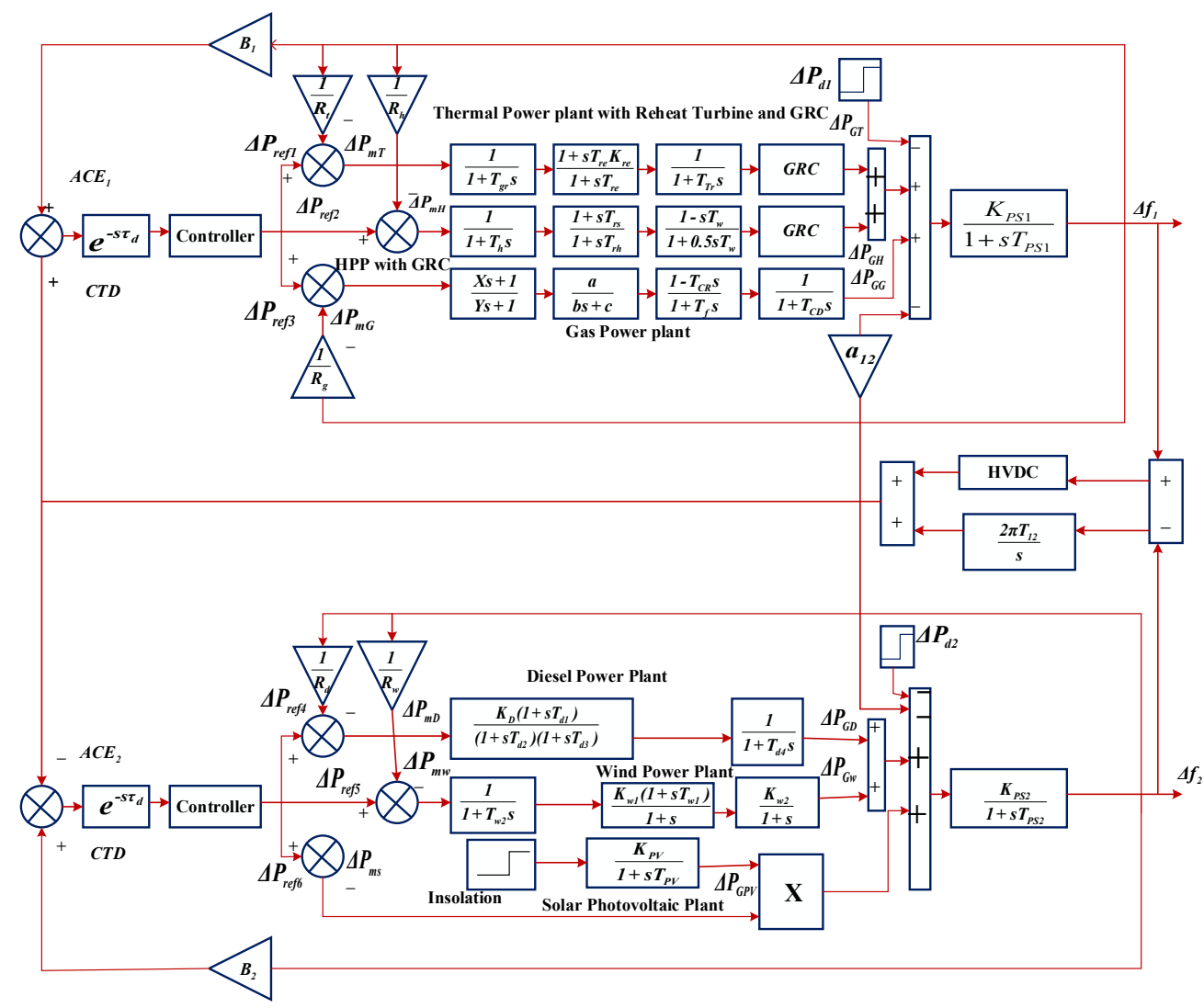

Figure 1. Transfer function model of multi-area multi-fuel power system. 


\section{Power System Model}

The power system model under investigation comprises two areas with a 2:1 ratio of generation capacities. Area 1 is integrated with conventional hydrothermal-gas power generation plants and area 2 is integrated with diesel-solar photovoltaic-wind units. The non-linearity feature of the generation rate constraint (GRC) is considered with the hydrothermal units, to conduct an analysis close to realistic practice. For the thermal plant, a $3 \% / \mathrm{min}$ GRC is considered, whereas for the hydro units $360 \% / \mathrm{min}$ and $270 \% / \mathrm{min}$ constraints are considered for valve lowering and raising. The model of the power system depicted in Figure 1 was developed using the MATLAB/Simulink version R2016a platform, and the required parameters were taken from [31]. Individual generation units are approximated by transfer functions as follows:

$$
\frac{\Delta \mathrm{P}_{\mathrm{GT}}(\mathrm{S})}{\Delta \mathrm{P}_{\mathrm{mT}}(\mathrm{S})}=\frac{\left(1+\mathrm{ST}_{\mathrm{re}} \mathrm{K}_{\mathrm{re}}\right)}{\left(1+\mathrm{T}_{\mathrm{gr}} \mathrm{S}\right)\left(1+\mathrm{ST}_{\mathrm{re}}\right)\left(1+\mathrm{T}_{\mathrm{Tr}} \mathrm{S}\right)}
$$

Hydro unit:

$$
\frac{\Delta \mathrm{P}_{\mathrm{GH}}(\mathrm{S})}{\Delta \mathrm{P}_{\mathrm{mH}}(\mathrm{S})}=\frac{\left(1+\mathrm{ST}_{\mathrm{rs}}\right)\left(1-\mathrm{ST}_{\mathrm{W}}\right)}{\left(1+\mathrm{T}_{\mathrm{h}} \mathrm{S}\right)\left(1+\mathrm{T}_{\mathrm{rh}} \mathrm{S}\right)\left(1+0.5 \mathrm{~T}_{\mathrm{W}} \mathrm{S}\right)}
$$

Gas unit:

$$
\frac{\Delta \mathrm{P}_{\mathrm{GG}}(\mathrm{S})}{\Delta \mathrm{P}_{\mathrm{mG}}(\mathrm{S})}=\frac{(1+\mathrm{XS})\left(1-\mathrm{T}_{\mathrm{CR}} \mathrm{S}\right) \mathrm{a}}{(1+\mathrm{YS})(\mathrm{c}+\mathrm{bS})\left(1+\mathrm{T}_{\mathrm{F}} \mathrm{S}\right)\left(1+\mathrm{T}_{\mathrm{CD}} \mathrm{S}\right)}
$$

Diesel unit:

$$
\frac{\Delta \mathrm{P}_{\mathrm{GD}}(\mathrm{S})}{\Delta \mathrm{P}_{\mathrm{mD}}(\mathrm{S})}=\frac{\mathrm{K}_{\mathrm{D}}\left(1+\mathrm{ST}_{\mathrm{d} 1}\right)}{\left(1+\mathrm{T}_{\mathrm{d} 4} \mathrm{~S}\right)\left(1+\mathrm{T}_{\mathrm{d} 2} \mathrm{~S}\right)\left(1+\mathrm{T}_{\mathrm{d} 3} \mathrm{~S}\right)}
$$

Wind unit:

$$
\frac{\Delta \mathrm{P}_{\mathrm{GW}}(\mathrm{S})}{\Delta \mathrm{P}_{\mathrm{mW}}(\mathrm{S})}=\frac{\mathrm{K}_{\mathrm{W} 1} \mathrm{~K}_{\mathrm{W} 2}\left(1+\mathrm{ST}_{\mathrm{W} 1}\right)}{\left(1+\mathrm{T}_{\mathrm{W} 2} \mathrm{~S}\right)\left(1+2 \mathrm{~S}+\mathrm{S}^{2}\right)}
$$

Solar photovoltaic unit:

$$
\frac{\Delta \mathrm{P}_{\mathrm{GPV}}(\mathrm{S})}{\varphi}=\frac{\mathrm{K}_{\mathrm{PV}}}{1+\mathrm{T}_{\mathrm{PV}} \mathrm{S}}
$$

The power generated by the individual units in area 1 and area 2 is modeled as

$$
\begin{gathered}
P_{G 1}=P_{G T}+P_{G H}+P_{G G} \\
P_{G 2}=P_{G D}+P_{G W}+P_{G P V}
\end{gathered}
$$

During perturbed conditions, the variation in power generated by the units in area 1 and area 2 is modeled as

$$
\begin{gathered}
\Delta \mathrm{P}_{\mathrm{G} 1}=\Delta \mathrm{P}_{\mathrm{GT}}+\Delta \mathrm{P}_{\mathrm{GH}}+\Delta \mathrm{P}_{\mathrm{GG}} \\
\Delta \mathrm{P}_{\mathrm{G} 2}=\Delta \mathrm{P}_{\mathrm{GD}}+\Delta \mathrm{P}_{\mathrm{GW}}+\Delta \mathrm{P}_{\mathrm{GPV}}
\end{gathered}
$$

The exchange of power between the areas with only an AC tie line is given as

$$
\mathrm{P}_{\text {tieAC }}=\mathrm{P}_{12} \sin \left(\delta_{1}-\delta_{2}\right)
$$

During perturbed conditions, Equation (11) can be redefined as

$$
\begin{aligned}
\Delta \mathrm{P}_{\text {tieAC }} & =\mathrm{T}_{12}\left(\Delta \delta_{1}-\Delta \delta_{2}\right) \\
& =\mathrm{T}_{12}\left(\Delta \mathrm{f}_{1}-\Delta \mathrm{f}_{2}\right)
\end{aligned}
$$

With the incorporation of the HVDC link in parallel with the existing AC line, power flow deviations can be controlled up to a certain level. The HVDC link cannot be designed 
without considering the model of the power system. The gain $\left(\mathrm{K}_{\mathrm{DC}}\right)$ and time $\left(\mathrm{T}_{\mathrm{DC}}\right)$ parameters of the HVDC line are optimized using the optimization technique. Power flow in the AC/DC tie line is defined as in Equation (13), and the single-line representation of the MAMF system with AC/DC lines is shown in Figure 2.

$$
\mathrm{P}_{\text {tie12 }}=\mathrm{P}_{\mathrm{tieAC}}+\mathrm{P}_{\mathrm{tieDC}}
$$

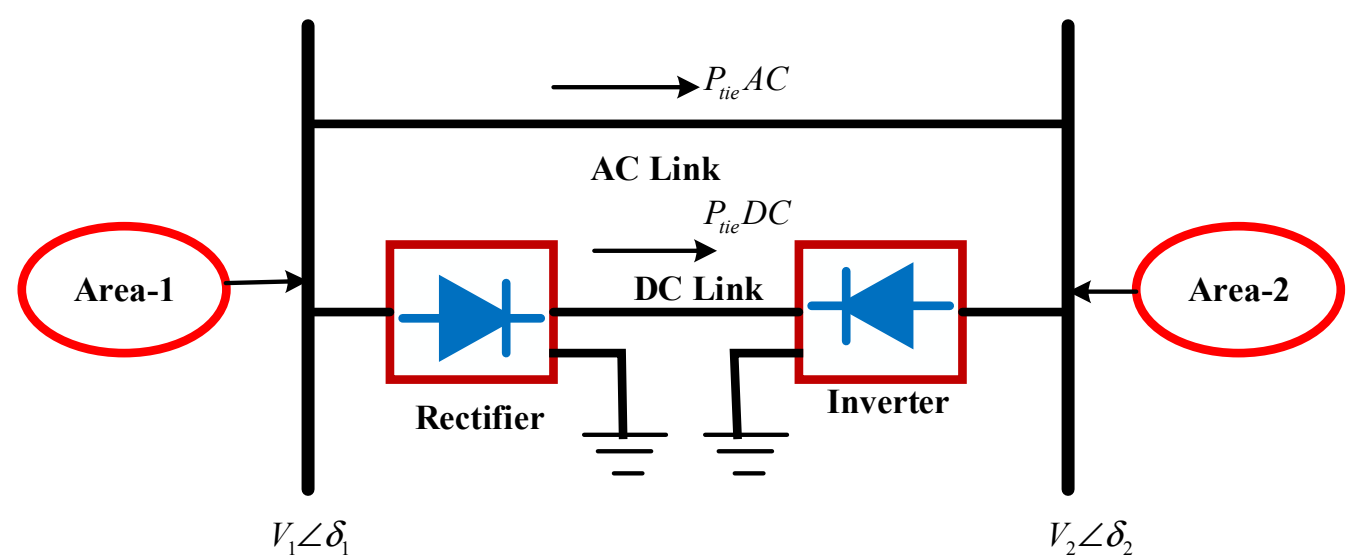

Figure 2. Single-line diagram of interconnected power system with AC/DC lines.

The change in power flow via the DC line under perturbing conditions is modeled as

$$
\Delta \mathrm{P}_{\mathrm{tieDC}}=\frac{\mathrm{K}_{\mathrm{DC}}}{\left(1+\mathrm{T}_{\mathrm{DC}} \mathrm{S}\right)}\left(\Delta \mathrm{f}_{1}-\Delta \mathrm{f}_{2}\right)
$$

Modeling of the area control error (ACE) with AC/DC tie-lines is given by

$$
\begin{aligned}
& \mathrm{ACE}_{1}=\mathrm{B}_{1} \Delta \mathrm{f}_{1}+\left(\Delta \mathrm{P}_{\text {tieAC }}+\Delta \mathrm{P}_{\text {tieDC }}\right) \\
& \mathrm{ACE}_{2}=\mathrm{B}_{2} \Delta \mathrm{f}_{2}+\left(\Delta \mathrm{P}_{\text {tieAC }}+\Delta \mathrm{P}_{\text {tieDC }}\right)
\end{aligned}
$$

\section{Communication Time Delays}

The modern-day IPS has become very complex with the penetration of different distributed generation (DG) sources. Usually, the power system network is situated in a vast area and has more sensing and phase-measuring devices in remote terminal locations. The measured data from devices located in remote terminals are transmitted to the command control center. Control signals, generated from the command control center based on the data received from remote devices, are transmitted to the secondary regulator in the plant location to alter the operating point of the system with respect to the varying load demand. The transmission and reception of signals among various devices located at large distances are achieved via communication channels. Communication channels are characterized by certain time delays, as data communication cannot take place instantly. Due to these CTDs, the delay in altering the power plant operating point leads to an increase in the real power mismatch between load and generation. These real power mismatches lead to fluctuations in system frequency, thereby affecting the power system stability. Moreover, in the case of severe CTDs, the designed secondary regulator may not handle the fluctuations and may become unstable. To overcome the instability issues due to the emergence of unintentional time delays within the system, the power system model must be considered with CTDs, and the secondary regulator must be designed in the presence of CTDs. The modeling of the CTDs considered in this paper is as follows [31]:

$$
\mathrm{e}^{-\mathrm{s} \tau_{\mathrm{d}}}=\frac{1-\frac{\tau_{\mathrm{d}}}{2} \mathrm{~s}}{1+\frac{\tau_{\mathrm{d}}}{2} \mathrm{~s}}
$$




\section{Controller and Objective Function}

Usually, traditional controllers such as I/PI/PID controllers are extensively adopted by researchers to regulate the power system frequency, due to their easy implementation and design simplicity. However, these classical controllers are not competent enough during uncertainties or for power system models with non-linear features. Fuzzy logic controllers (FLC) are the most efficient for handling non-linear systems [32]. However, the design of the FLC interface and the selection of the membership functions (MFs) requires the utmost care. Otherwise, the FLC may degrade the power system performance. Triangular MFs, as shown in Figure 3, were chosen for the FLC in this study, because of their simplicity and low memory utilization. Moreover, these triangular MFs with an overlap of $50 \%$ yield satisfactory results. Triangular MFs with linguistic variables such as (LP) large positive, (SP) small positive, (Z) zero, (SN) small negative and (LN) large negative [33] were considered. The area control error (ACE) and the derivative of the ACE were given as input to the FLC unit, and then the output of the FLC was fed to the PID to generate the final output to shift the operating point subjected to load fluctuations. The fuzzy PID structure utilized in this work is depicted in Figure 4 [34].

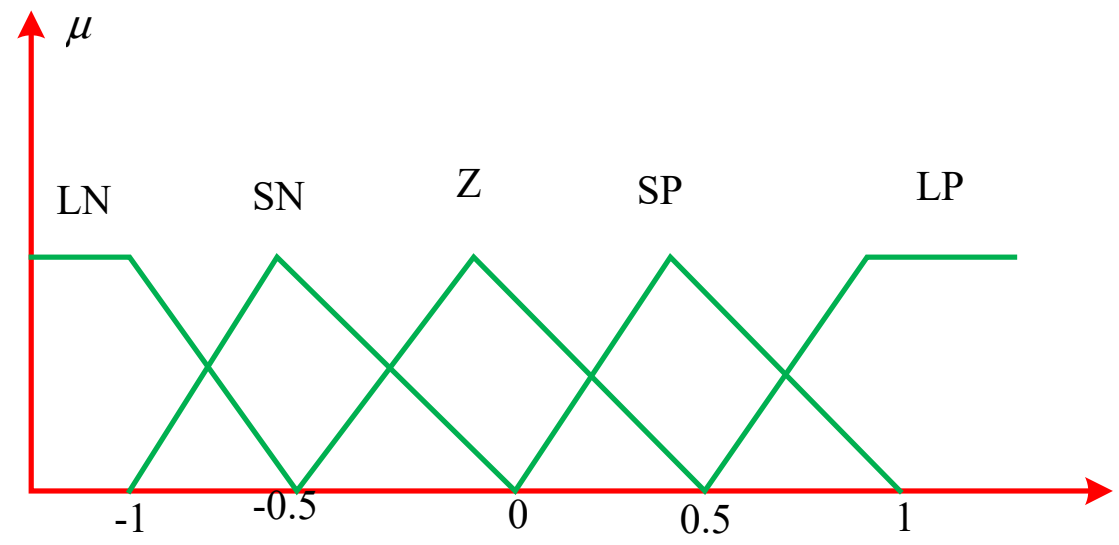

Figure 3. Fuzzy membership functions.

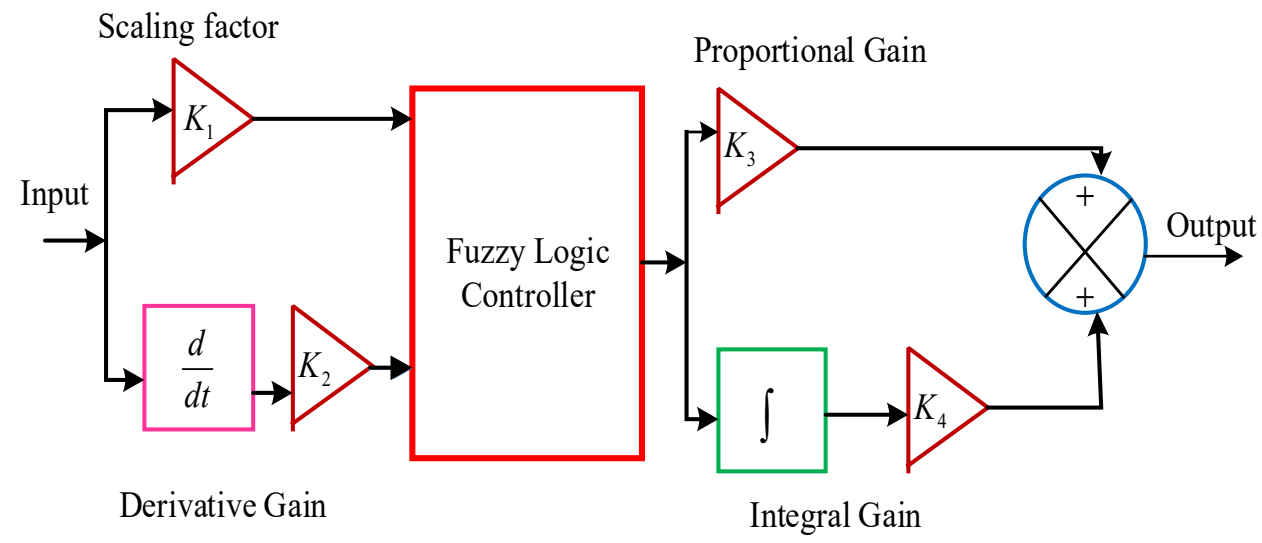

Figure 4. Structure of fuzzy-aided PID controller [34].

A Mamdani-type FLC system was designed in this work, with the center of gravity method [35,36] of defuzzification. The fuzzy output was calculated based on the rules shown in Table 1. The gains of the fuzzy-aided PID were optimized using the metaheuristic optimization approach of a WCA subjected to the minimization of the ISE objective function. Compared to other time-domain-based objective functions, ISE is more effective 
in dampening peak deviations by maintaining the average balance with settling time. Therefore, we adopted ISE in this work, as shown in Equation (18).

$$
\mathrm{J}_{\text {ISE }}=\int_{0}^{\mathrm{T}_{\text {Sim }}}\left(\Delta \mathrm{f}_{1}^{2}+\Delta \mathrm{P}_{\text {tie12 }}^{2}+\Delta \mathrm{f}_{2}^{2}\right)
$$

Table 1. FLC system input and output rules.

\begin{tabular}{cccccc}
\hline \multirow{2}{*}{ ACE } & \multicolumn{5}{c}{$\Delta$ ACE } \\
\cline { 2 - 6 } & LN & SN & Z & SP & LP \\
\hline LN & LN & LN & LN & SN & Z \\
SN & LN & LN & SN & Z & SP \\
Z & LN & SN & Z & SP & LP \\
SP & SN & Z & SP & LP & LP \\
LP & LP & Z & SP & LP & LP \\
\hline
\end{tabular}

\section{Water Cycle Algorithm}

The water cycle algorithm (WCA) is one of the newest population-based meta-heuristic optimization techniques that many researchers are focusing on, especially for constrained engineering optimization problems. The evolution of this algorithm, introduced by Eskander et al. [37] in 2012, was inspired by the phenomena of the water cycle on the Earth's surface. Since then, this approach has found applications in many research fields. However, the implementation of the WCA approach in power system regulation has not been significant to date. This motivated the researchers in this study to implement this searching algorithm to find the optimal parameters of the secondary regulator to regulate the frequency and maintain the stability of interconnected power system models.

The searching strategy of the WCA starts with an initial population of raindrops or snowflakes that accumulate on hills or mountains and later collectively move downwards to form streams and rivers. Finally, these streams and rivers are assumed to be joined at the sea, treated as the global best solution.

For a solution with variables $1 \times \mathrm{N}_{\mathrm{var}}$, the vector of rain drops (RD) is formulated as

$$
\begin{aligned}
& R D_{i}=Y_{i}=\left[y_{1}, y_{2} \ldots \ldots . y_{N v a r}\right] \\
& \mathrm{RD} \text { Population }=\left[\begin{array}{c}
\mathrm{RD}_{1} \\
-- \\
\mathrm{RD}_{\mathrm{i}} \\
-- \\
\mathrm{RD}_{\mathrm{N}_{\mathrm{POP}}}
\end{array}\right]
\end{aligned}
$$

After defining the initial population, the cost of an individual RD is evaluated considering the time-domain objective index of ISE, as formulated in Equation (18).

Subsequently, the positions (P) of rivers/streams are updated, as shown in Equations (21) and (22), based on the assumption that these join at the sea eventually.

$$
\begin{gathered}
\mathrm{P}_{\text {stream }}^{\text {new }}=\mathrm{P}_{\text {stream }}+\operatorname{rand}() * \mathrm{C} *\left(\mathrm{P}_{\text {river }}-\mathrm{P}_{\text {stream }}\right) \\
\mathrm{P}_{\text {river }}^{\text {new }}=\mathrm{P}_{\text {river }}+\operatorname{rand}() * \mathrm{C} *\left(\mathrm{P}_{\text {sea }}-\mathrm{P}_{\text {river }}\right)
\end{gathered}
$$

The parameter $\mathrm{C}$ is constant and is generated randomly, taking a value lying between 0 and 2, whereas rand () takes a value between 0 and 1 . If the evaluated cost index value of the stream happens to be less than that of the river, then the positions of the stream and river will be exchanged. A similar process is applied for rivers and the sea.

To facilitate space for rainwater in the sea, the optimization algorithm is operated with an evaporation phase for seawater. Further, this loop will avoid rapid convergence 
and impart excellent capability to the searching mechanism. The phase of evaporation terminates if

$$
\left|\mathrm{P}_{\text {sea }}-\mathrm{P}_{\text {river }}\right|<\mathrm{d}_{\max }
$$

where $\mathrm{d}_{\max }$ is a number close to zero, which decreases automatically as

$$
\mathrm{d}_{\max }^{\text {new }}=\mathrm{d}_{\max }-\left(\mathrm{d}_{\max } / \text { max.iteration }\right)
$$

The phase of rain starts immediately after the termination of the evaporation process. During rain, new streams will be formed at different locations, and their positions are found using

$$
\mathrm{P}_{\text {stream }}^{\text {new }}=\mathrm{P}_{\text {sea }}+\sqrt{\mathrm{U}} \times \operatorname{rand}\left(1, \mathrm{~N}_{\mathrm{var}}\right)
$$

where $U$ indicates the rate of search close to the sea. The algorithm displays the global best solution when it reaches the maximum iteration count. The parametric values implemented while designing the WCA algorithm for power system optimization in this study are given in Table 2, and the flowchart is depicted in Figure 5.

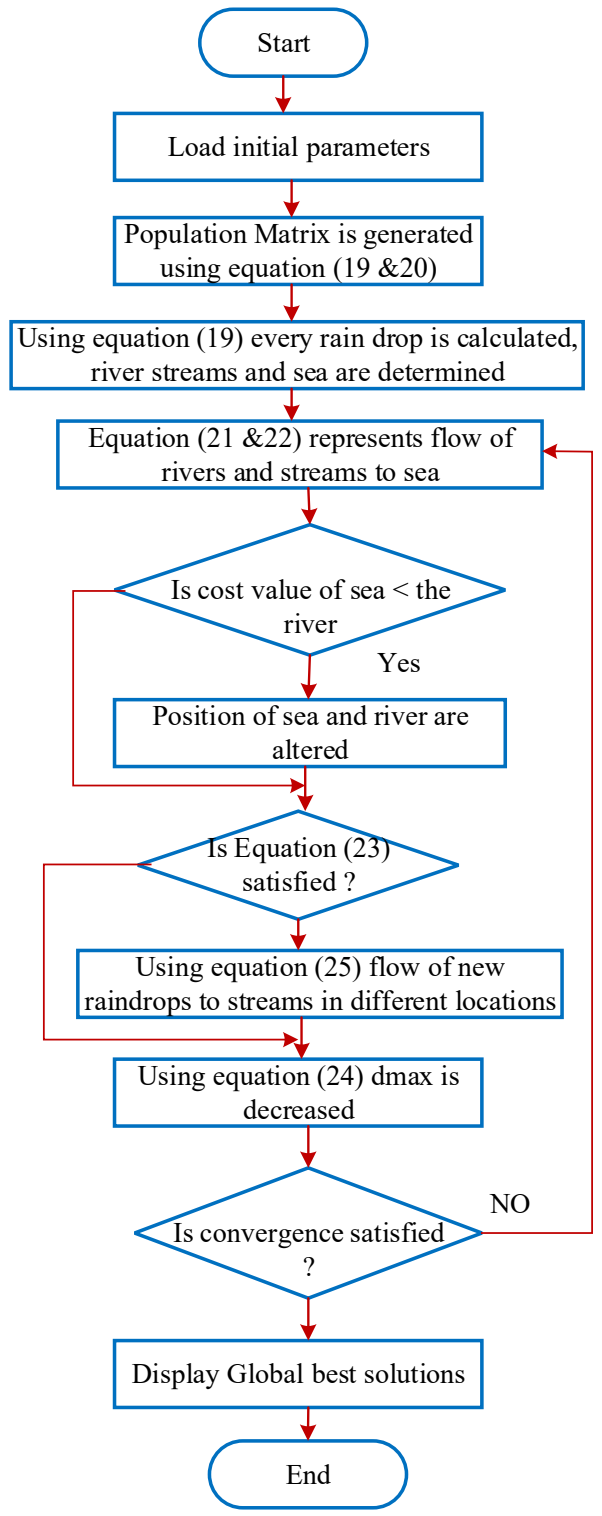

Figure 5. WCA flowchart. 
Table 2. WCA parameters.

\begin{tabular}{cc}
\hline Parameter & Value \\
\hline$N_{\text {Var }}$ & 21 \\
$N_{P O P}$ & 100 \\
$\mathrm{C}$ & 2 \\
$\mathrm{U}$ & 0.04 \\
$d_{\max }$ & 0.001 \\
Max.iteration & 50 \\
\hline
\end{tabular}

\section{Simulation Results}

\subsection{Case 1: Analysis of MAMF System without Considering CTDs}

The performance of the MAMF system was assessed without taking the feature of CTDs into account. Various controllers such as PID/PIDD/fuzzy PID were implemented as secondary regulators one after the other in both the areas, and were optimized using the WCA algorithm. To obtain the most comparative analysis, responses under different controllers are compared in Figure 6 in terms of frequency deviation in area $1\left(\Delta \mathrm{f}_{1}\right)$ and area $2\left(\Delta \mathrm{f}_{2}\right)$, and tie-line power flow deviations $\left(\Delta \mathrm{P}_{\text {tie12 }}\right)$. Moreover, the responses shown in Figure 6 are numerically interpolated with regard to the settling time $\left(T_{s}\right)$ provided in Table 3, and the controller's optimum gains are noted in Table 4. Further, the peak undershoot $\left(\mathrm{U}_{\mathrm{S}}\right)$ values obtained with the presented FPID were lower $\left(\Delta \mathrm{f}_{1}=0.0098 \mathrm{~Hz}\right.$, $\left.\Delta \mathrm{P}_{\text {tie12 }}=0.00541 \mathrm{Pu} . \mathrm{MW}, \Delta \mathrm{f}_{2}=0.000303 \mathrm{~Hz}\right)$ than those using PIDD $\left(\Delta \mathrm{f}_{1}=0.01311 \mathrm{~Hz}\right.$, $\left.\Delta \mathrm{P}_{\text {tie12 }}=0.00868 \mathrm{Pu} . \mathrm{MW}, \Delta \mathrm{f}_{2}=0.00068 \mathrm{~Hz}\right)$ and $\mathrm{PID}\left(\Delta \mathrm{f}_{1}=0.01659 \mathrm{~Hz}, \Delta \mathrm{P}_{\text {tie12 }}=0.01315\right.$ Pu.MW, $\Delta \mathrm{f}_{2}=0.001021 \mathrm{~Hz}$ ). From Figure 6 and Table 3, it can be primarily concluded that the fuzzy PID completely outperforms the PID/PIDD in diminishing the peak undershoots/overshoots as well as in damping out the oscillations. Further, with the fuzzy PID, the objective index is very slightly minimized, whereas it is enhanced by $60.94 \%$ with PIDD and $78.63 \%$ with PID.

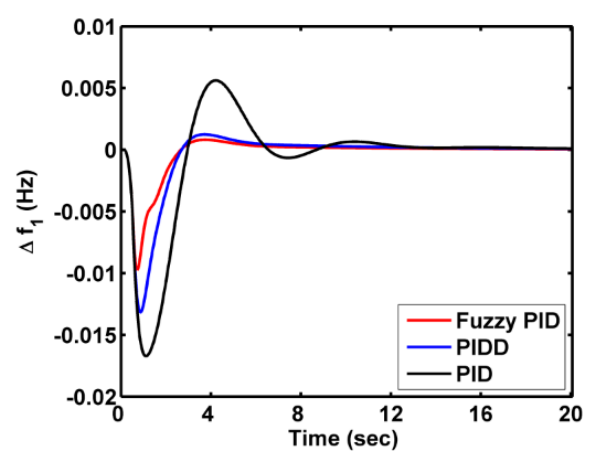

(a)

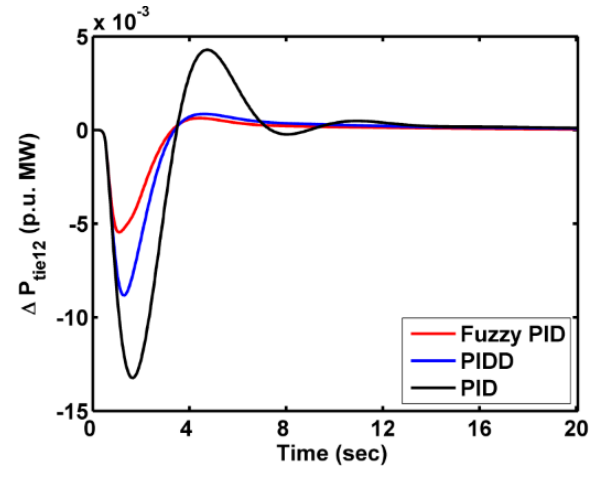

(b)

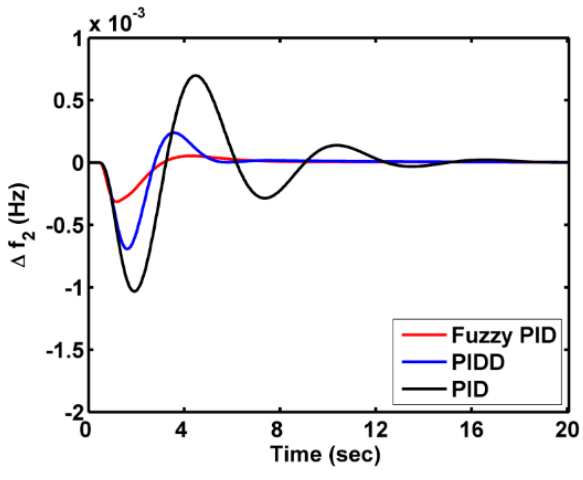

(c)

Figure 6. MAMF system responses for case $1:$ (a) $\Delta \mathrm{f}_{1} ;$ (b) $\Delta \mathrm{P}_{\text {tie12 }} ;$ (c) $\Delta \mathrm{f}_{2}$.

Table 3. MAMF system response settling time (in sec) for various cases.

\begin{tabular}{ccccccc}
\hline \multirow{2}{*}{$\begin{array}{c}\text { Settling Time } \\
\text { (in sec) }\end{array}$} & FPID & PIDD & PID & FPID & PIDD & PID \\
\cline { 2 - 7 } & 7.56 & 8.95 & 12.69 & 9.721 & 11.88 & 15.97 \\
$\Delta \mathrm{f}_{1}$ & 10.160 & 11.46 & 13.21 & 11.23 & 12.40 & 14.26 \\
$\Delta \mathrm{P}_{\text {tie12 }}$ & 8.322 & 11.80 & 14.89 & 9.834 & 13.16 & 16.39 \\
$\Delta \mathrm{f}_{2}$ & 7.769 & 19.893 & 36.355 & 29.275 & 52.283 & 85.098 \\
$\mathrm{ISE} \times 10^{-3}$ & & & & &
\end{tabular}


Table 4. MAMF system response settling time (in sec) for various cases.

\begin{tabular}{|c|c|c|c|c|c|c|}
\hline \multirow{2}{*}{ Controller } & \multicolumn{3}{|c|}{ Area 1} & \multicolumn{3}{|c|}{ Area 2} \\
\hline & FPID & PIDD & PID & FPID & PIDD & PID \\
\hline Case 1 & $\begin{array}{l}\mathrm{K}_{1}=0.5757 \\
\mathrm{~K}_{2}=0.7573 \\
\mathrm{~K}_{3}=0.8315 \\
\mathrm{~K}_{4}=0.3394\end{array}$ & $\begin{array}{c}\mathrm{K}_{\mathrm{P}}=2.0755 \\
\mathrm{~K}_{\mathrm{I}}=1.1281 \\
\mathrm{~K}_{\mathrm{D}}=0.7329 \\
\mathrm{~K}_{\mathrm{DD}}=0.1430\end{array}$ & $\begin{array}{c}\mathrm{K}_{\mathrm{P}}=3.1388 \\
\mathrm{~K}_{\mathrm{I}}=2.0944 \\
\mathrm{~K}_{\mathrm{D}}=1.4939\end{array}$ & $\begin{array}{l}\mathrm{K}_{1}=0.8861 \\
\mathrm{~K}_{2}=0.6994 \\
\mathrm{~K}_{3}=0.8606 \\
\mathrm{~K}_{4}=0.3766\end{array}$ & $\begin{array}{c}\mathrm{K}_{\mathrm{P}}=1.9575 \\
\mathrm{~K}_{\mathrm{I}}=1.6113 \\
\mathrm{~K}_{\mathrm{D}}=0.5889 \\
\mathrm{~K}_{\mathrm{DD}}=0.1495\end{array}$ & $\begin{array}{l}\mathrm{K}_{\mathrm{P}}=2.9936 \\
\mathrm{~K}_{\mathrm{I}}=1.8112 \\
\mathrm{~K}_{\mathrm{D}}=0.8632\end{array}$ \\
\hline Case 2 & $\begin{array}{l}\mathrm{K}_{1}=0.5014 \\
\mathrm{~K}_{2}=0.7113 \\
\mathrm{~K}_{3}=0.6592 \\
\mathrm{~K}_{4}=0.4588\end{array}$ & $\begin{array}{c}\mathrm{K}_{\mathrm{P}}=1.8098 \\
\mathrm{~K}_{\mathrm{I}}=1.2760 \\
\mathrm{~K}_{\mathrm{D}}=0.9630 \\
\mathrm{~K}_{\mathrm{DD}}=0.0607\end{array}$ & $\begin{array}{l}K_{P}=2.9861 \\
K_{I}=1.9060 \\
K_{D}=1.1464\end{array}$ & $\begin{array}{l}\mathrm{K}_{1}=0.8130 \\
\mathrm{~K}_{2}=0.8248 \\
\mathrm{~K}_{3}=0.6416 \\
\mathrm{~K}_{4}=0.4268\end{array}$ & $\begin{array}{c}\mathrm{K}_{\mathrm{P}}=1.9623 \\
\mathrm{~K}_{\mathrm{I}}=1.2260 \\
\mathrm{~K}_{\mathrm{D}}=0.6232 \\
\mathrm{~K}_{\mathrm{DD}}=0.4939\end{array}$ & $\begin{aligned} K_{P} & =3.0283 \\
K_{I} & =2.0519 \\
K_{D} & =0.8964\end{aligned}$ \\
\hline
\end{tabular}

\subsection{Case 2: Analysis of MAMF System with CTDs Considered}

The MAMF system performance was assessed taking the feature of CTDs into account. A realistic time delay of $0.25 \mathrm{sec}$ was considered in this work, to analyze its impact on system performance. The WCA-optimized controllers such as PID/PIDD/fuzzy PID were implemented in the MAMF system one after another in both the areas for the same disturbance loading on area 1 of $10 \%$ SLD. The responses for this case are shown in Figure 7, and the corresponding numerical results are given in Table 3. From the responses depicted in Figure 7, it can be concluded that the fuzzy PID showed superior performance in handling the system behaviour, even when considering CTDs. Moreover, the peak $\mathrm{U}_{\mathrm{S}}$ values are greatly diminished with FPID $\left(\Delta \mathrm{f}_{1}=0.0187 \mathrm{~Hz}, \Delta \mathrm{P}_{\text {tie12 }}=0.01074 \mathrm{Pu} . \mathrm{MW}\right.$, $\left.\Delta \mathrm{f}_{2}=0.00064 \mathrm{~Hz}\right)$ compared with using PIDD $\left(\Delta \mathrm{f}_{1}=0.02033 \mathrm{~Hz}, \Delta \mathrm{P}_{\text {tiel2 }}=0.01293 \mathrm{Pu} . \mathrm{MW}\right.$, $\left.\Delta \mathrm{f}_{2}=0.00086 \mathrm{~Hz}\right)$ and PID $\left(\Delta \mathrm{f}_{1}=0.02569 \mathrm{~Hz}, \Delta \mathrm{P}_{\text {tie12 }}=0.01813 \mathrm{Pu} . \mathrm{MW}, \Delta \mathrm{f}_{2}=0.001359 \mathrm{~Hz}\right)$ The ISE index is greatly minimized by the fuzzy PID but is improved by $44.06 \%$ with PIDD and $65.59 \%$ with PID.

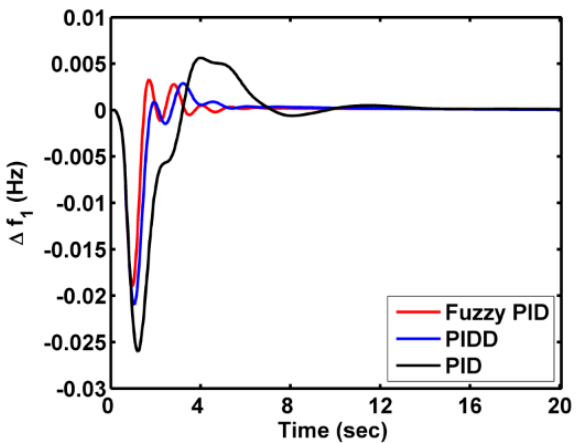

(a)

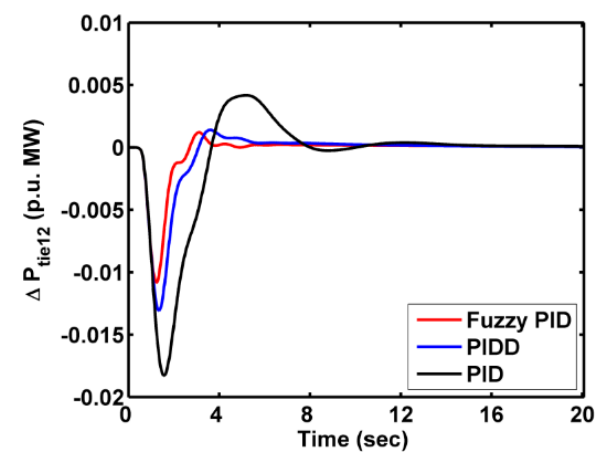

(b)

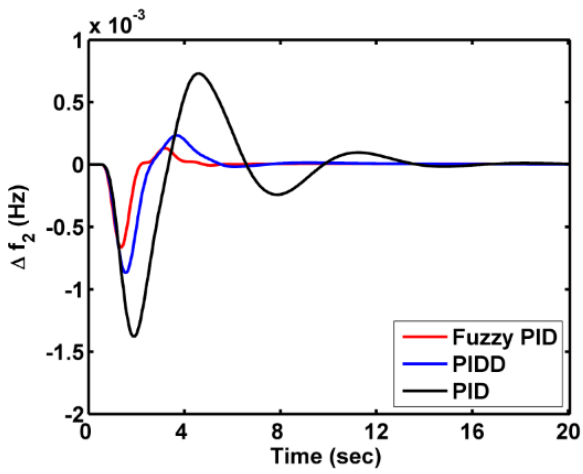

(c)

Figure 7. MAMF system responses for case 2 : (a) $\Delta \mathrm{f}_{1} ;$ (b) $\Delta \mathrm{P}_{\text {tie12 }} ;\left(\right.$ c) $\Delta \mathrm{f}_{2}$.

6.3. Case 3: Comparative Analysis of MAMF System Responses without and with Consideration of CTDs

To demonstrate the predominance of CTDs in the MAMF system performance, responses with and without considering CTDs under the supervision of the WCA-based fuzzy PID controller are compared in Figure 8. As the fuzzy PID exhibits more dominance in regulating the deviations in responses compared to the PID/PIDD, the responses under fuzzy PID only are compared in Figure 8. From the MAMF system responses compared in Figure 8, it can be concluded that the responses with CTDs have more deviations and take slightly more time for the oscillations to settle down. Moreover, the responses of the MAMF system with CTDs take more time to reach a steady condition. This is because of the time delay between transmission and reception of the measured data signals and control signals among different devices situated in various locations. With these time delays, the 
data from sensors installed at distant locations will be transmitted to the command control center with some delay. Based on these data, the control signal will be generated and fed as input to the regulator in the plant location to alter the real power generation subjected to a fluctuating load demand. Hence, the delay in generating the control signal and the delay in transmitting the control signal to the regulator in the plant location leads to a more real power mismatch between generation and demand and hence to deviations in the system dynamical behaviour. Thus, we strongly endorse considering the CTDs within the power system when designing the regulator, to avoid stability issues. A regulator designed without taking CTDs into account will no longer maintain system stability in the event of unintentional time delays emerging within the power system.

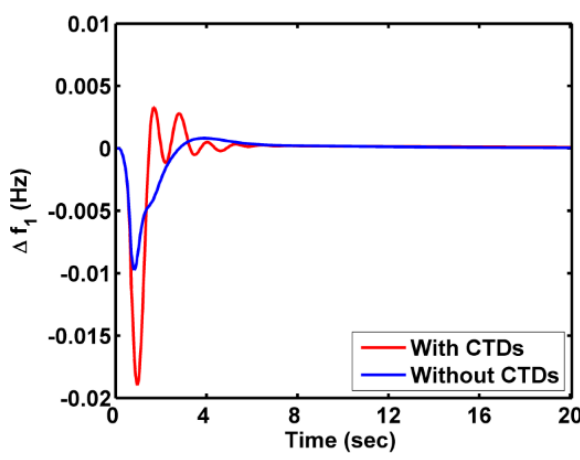

(a)

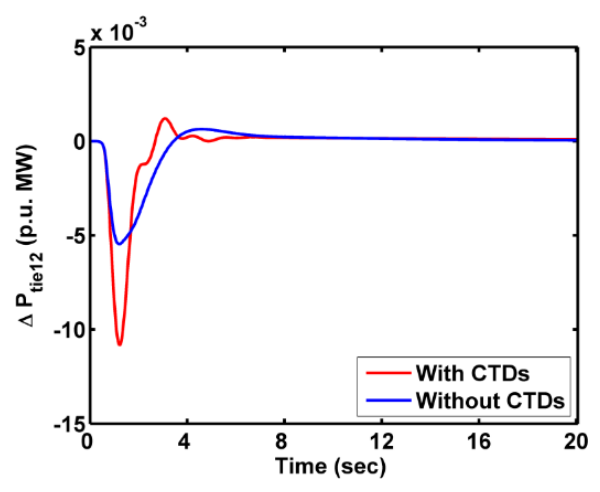

(b)

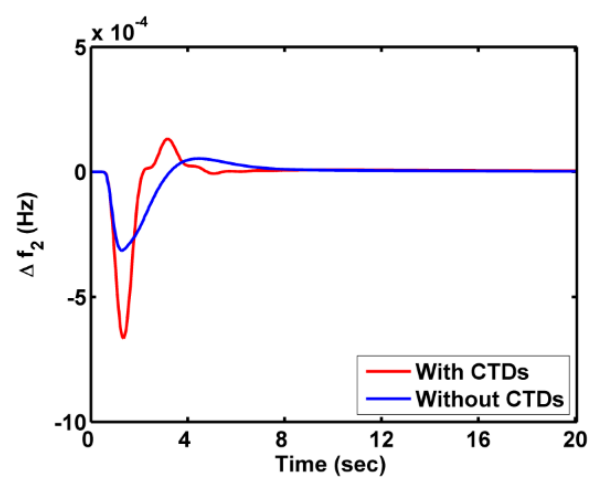

(c)

Figure 8. MAMF system responses for case 3: (a) $\Delta \mathrm{f}_{1} ;(\mathbf{b}) \Delta \mathrm{P}_{\text {tie12 }} ;$ (c) $\Delta \mathrm{f}_{2}$.

\subsection{Case 4: Analysis of MAMF System with AC/DC Lines}

To substantiate the oscillations that occur in the system dynamical behaviour because of CTDs and the deviations in peak undershoot/overshoot, an additional HVDC tie line was incorporated in the MAMF system in parallel with the existing AC line. The system responses with the AC line and AC/DC lines are compared in Figure 9, to visualize the efficacy of adopting the additional HVDC tie line in the system and numerical results are provided in Table 5. The deviations were greatly mitigated, and the responses settled down more quickly when employing AC/DC lines than when employing only AC lines. Thus, it is concluded that the territorial control strategy of employing AC/DC lines in the interconnected power system enhances the system dynamical behaviour.

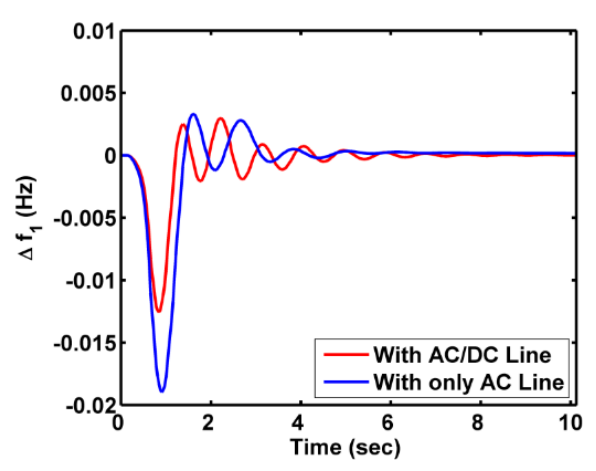

(a)

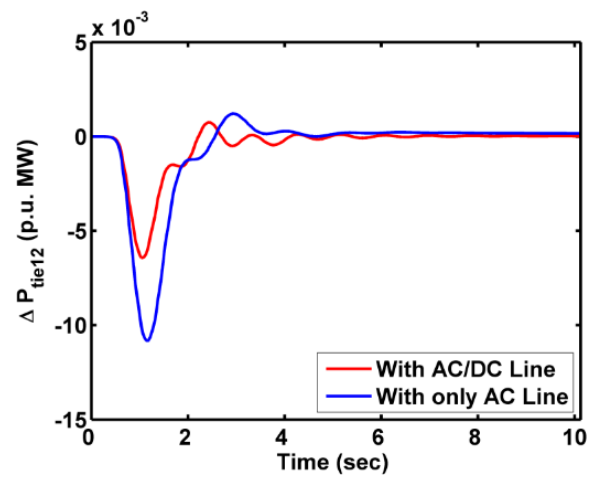

(b)

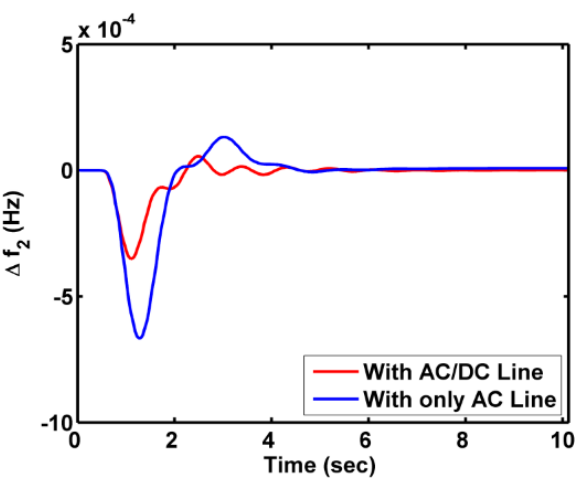

(c)

Figure 9. MAMF system responses for case 4 : (a) $\Delta \mathrm{f}_{1} ;$ (b) $\Delta \mathrm{P}_{\text {tie12 }} ;(\mathbf{c}) \Delta \mathrm{f}_{2}$. 
Table 5. MAMF system response settling time (in sec) for AC/DC lines.

\begin{tabular}{ccccc}
\hline Parameter & $\boldsymbol{\Delta f}_{\mathbf{1}}$ & $\mathbf{\Delta}_{\text {tie12 }}$ & $\boldsymbol{\Delta} \mathbf{f}_{\mathbf{2}}$ & $\mathbf{I S E} \times \mathbf{1 0}^{-\mathbf{3}}$ \\
\hline With AC line only & 9.721 & 11.23 & 9.834 & 29.275 \\
With AC/DC lines & 7.758 & 6.746 & 7.112 & 17.362 \\
\hline
\end{tabular}

\subsection{Case 5: Robustness Analysis}

To show the robustness of the presented control mechanism, the MAMF system with CTDs was subjected to loadings of $10 \%$ SLD on area 1 only, and 10\% SLD and 20\% SLD on both areas. Even though the system was subjected to different loadings, the deviations in system dynamical behaviour, as shown in Figure 10, are not marked. Thus, the presented control strategy of the fuzzy PID and the territorial control strategy of AC/DC lines were considered robust. Further, to validate the presented control scheme, the MAMF system was targeted with random loadings, as shown in Figure 11.

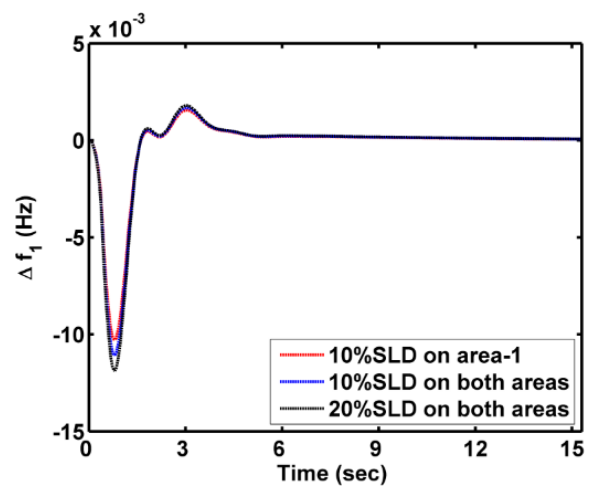

(a)

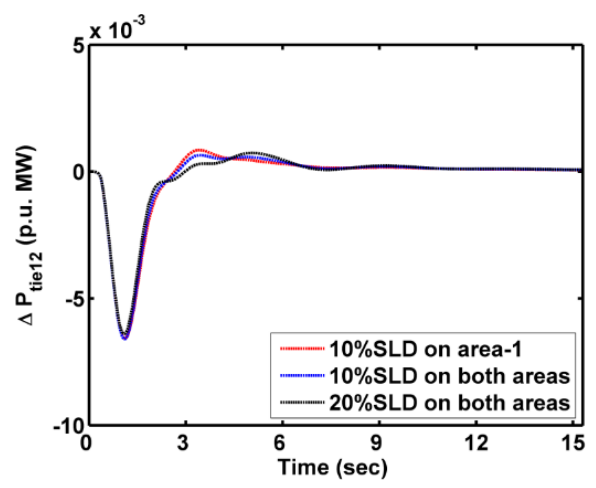

(b)

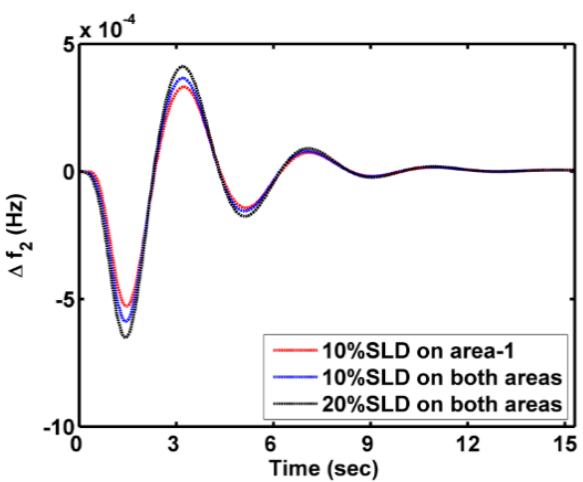

(c)

Figure 10. MAMF system responses for case 5 for different loadings: (a) $\Delta \mathrm{f}_{1} ;$ (b) $\Delta \mathrm{P}_{\text {tie12 }} ;$ (c) $\Delta \mathrm{f}_{2}$.

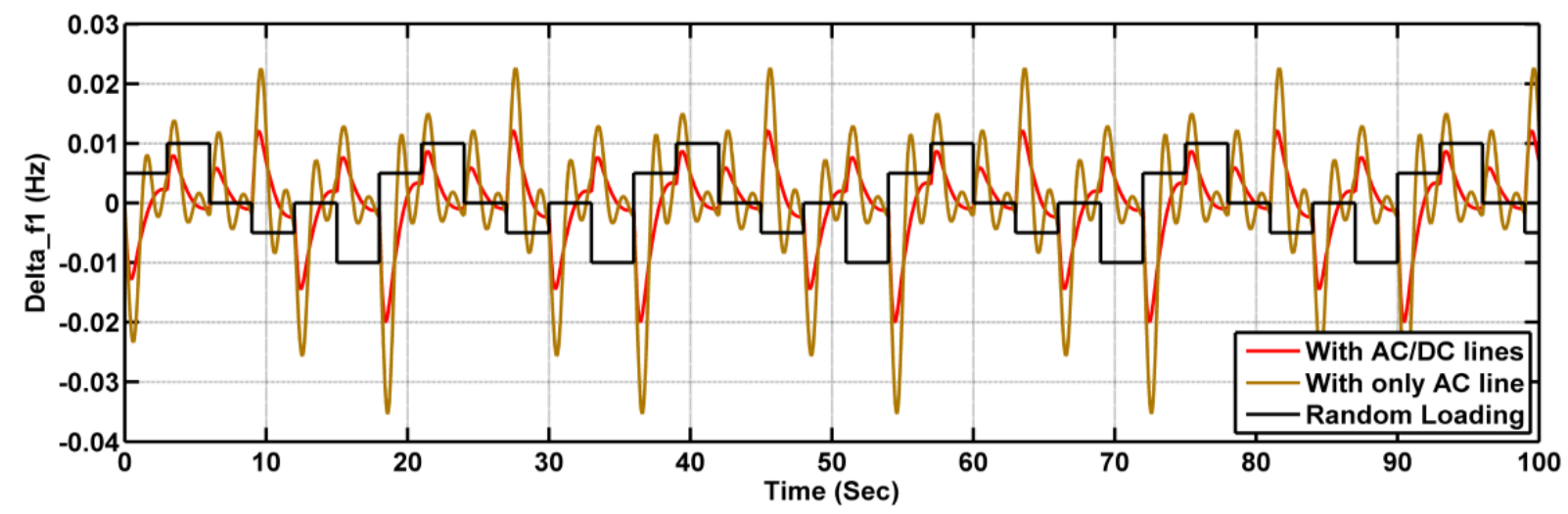

(a)

Figure 11. Cont. 


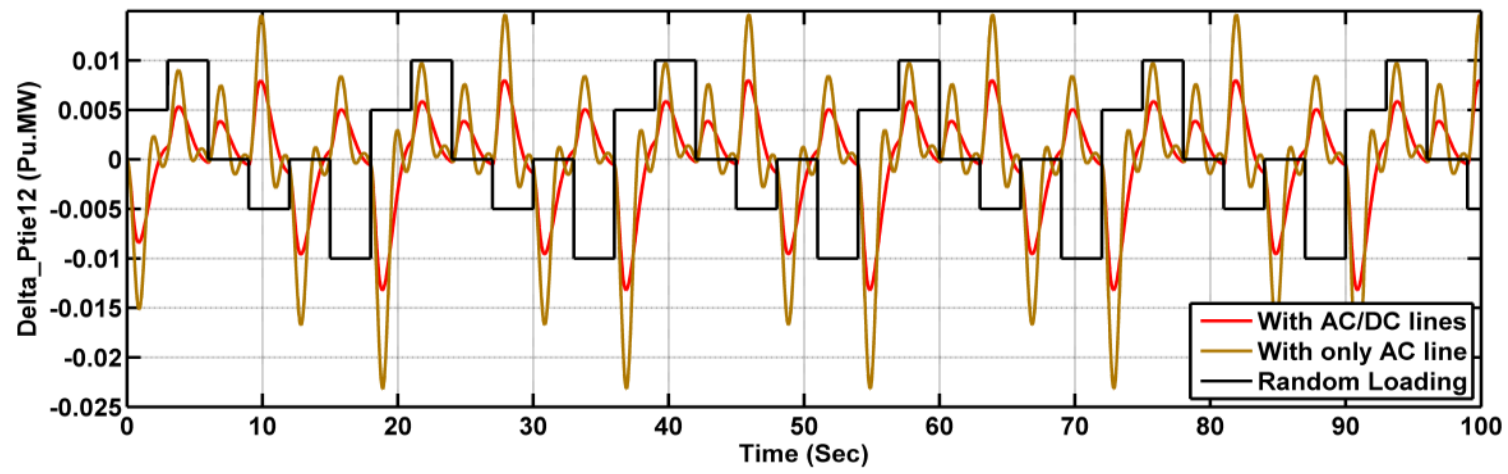

(b)

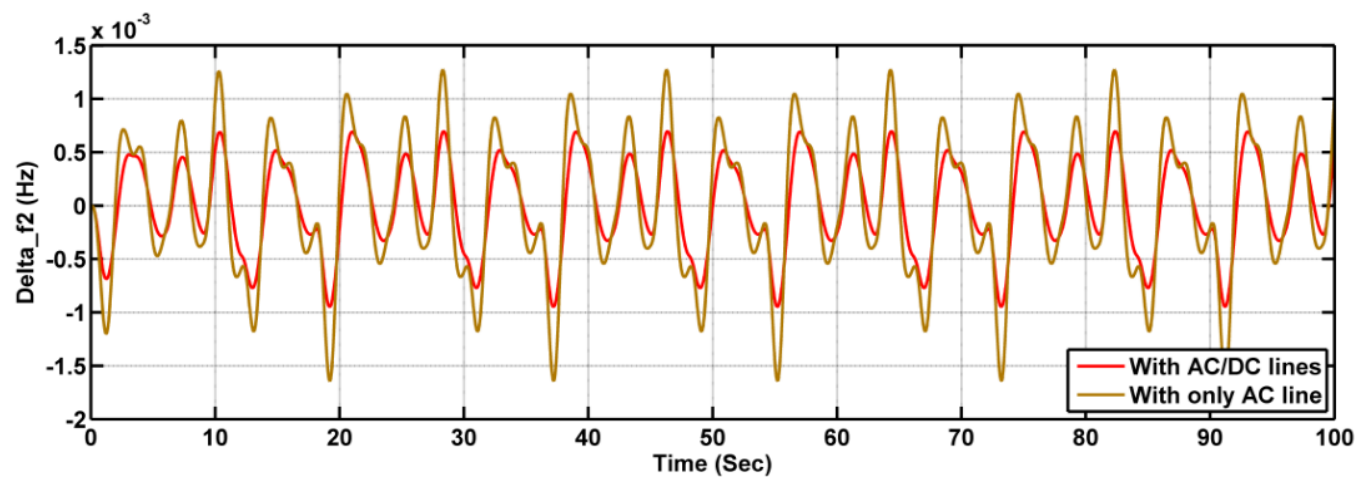

(c)

Figure 11. MAMF system responses for case 5 for random loadings: (a) $\Delta \mathrm{f}_{1} ;$ (b) $\Delta \mathrm{P}_{\text {tie12 }} ;$ (c) $\Delta \mathrm{f}_{2}$.

\section{Conclusions}

In this paper, a WCA-tuned fuzzy PID controller was suggested for frequency regulation of the MAMF power system. The efficacy of fuzzy PID was demonstrated, compared with the performance of traditional PID/PIDD. The dynamical behaviour of the MAMF system was analyzed by subjecting area 1 to $10 \%$ SLD. Moreover, the investigation was performed on the MAMF system without and with consideration of CTDs, to exhibit their dominance with regard to the system performance. To further substantiate the fluctuations in the MAMF system responses due to the effect of CTDs, a territorial control strategy of $\mathrm{AC} / \mathrm{DC}$ lines was operated within the system. The simulation results demonstrated the effect of the AC/DC line on the MAMF system performance in damping out the fluctuations in less time. Furthermore, considering the advantages of fuzzy PID, we suggest adopting and testing the efficacy of FO-based intelligent FLC controllers for stability analysis of interconnected power systems considering CTDs in future work.

Author Contributions: Conceptualization, C.N.S.K., M.B. and S.K.; Data curation, B.S.G., M.K.K. and E.M.A.; Formal analysis, C.N.S.K. and M.B.; Funding acquisition, B.S.G., E.M.A. and S.K.; Investigation, C.N.S.K., B.S.G., M.B. and M.K.K.; Methodology, B.S.G., E.M.A. and S.K.; Project administration, C.N.S.K. and M.B.; Resources, B.S.G., M.K.K., E.M.A. and S.K.; Software, C.N.S.K., B.S.G. and M.K.K.; Supervision, B.S.G., M.B. and S.K.; Validation, M.K.K. and E.M.A.; Visualization, C.N.S.K., M.B. and S.K.; Writing - original draft, C.N.S.K. and B.S.G.; Writing - review \& editing, M.B., M.K.K., E.M.A. and S.K. All authors have read and agreed to the published version of the manuscript.

Funding: This work is funded by the Deanship of Scientific Research at Jouf University under grant No (DSR-2021-02-0307).

Institutional Review Board Statement: Not applicable.

Informed Consent Statement: Not applicable. 
Data Availability Statement: Not applicable.

Conflicts of Interest: The authors declare no conflict of interest.

$\begin{array}{ll}\text { Abbreviations } \\ \text { SLD } & \text { Step load disturbance } \\ \text { AGC } & \text { Automatic generation control } \\ \text { CTDs } & \text { Communication time delays } \\ \text { IPS } & \text { Interconnected power system } \\ \text { LFC } & \text { Load frequency control } \\ \text { DG } & \text { Distributed generation } \\ \text { MAMF } & \text { Multi-area multi-fuel } \\ \text { GDB } & \text { Governor dead band } \\ \text { GRC } & \text { Generation rate constraint } \\ \text { HVDC } & \text { High-voltage DC line } \\ \text { WCA } & \text { Water cycle algorithm } \\ \text { COG } & \text { Center of gravity } \\ \text { MFs } & \text { Membership functions } \\ \text { ISE } & \text { Integral square error } \\ \text { ACE } & \text { Area control error }\end{array}$

\section{References}

1. Cohen, N. Some aspects of tie-line bias control on interconnected power systems. Trans. Am. Inst. Electr. Eng. Part III Power Appar. Syst. 1957, 75, 1415-1436.

2. Elgerd, O.; Fosha, E. Optimum megawatt-frequency control of multi-area electric energy systems. IEEE Trans. Power Appar. Syst. 1970, 84, 556-563. [CrossRef]

3. Latif, A.; Hussain, S.M.; Das, D.C.; Ustun, T.S. State-of-the-art of controllers and soft computing techniques for regulated load frequency management of single/multi-area traditional and renewable energy based power systems. Appl. Energy 2020, 266, 114858. [CrossRef]

4. Chandrakala, K.R.M.V.; Balamurugan, S. Simulated annealing based optimal frequency and terminal voltage control of multisource multi area system. Int. J. Electr. Power Energy Syst. 2016, 78, 823-829. [CrossRef]

5. Dogan, A. Load frequency control of two area and multi source power system using grey wolf optimization algorithm. In Proceedings of the 11th International Conference on Electrical and Electronics Engineering (ELECO), Bursa, Turkey, 28-30 November 2019; pp. 81-84.

6. $\quad$ Elsaied, M.M.; Attia, M.A.; Mostafa, M.A.; Mekhamer, S.F. Application of different optimization techniques to load frequency control with WECS in a multi-area system. Electr. Power Compon. Syst. 2018, 46, 739-756. [CrossRef]

7. Guha, D.; Roy, P.K.; Banerjee, S. Application of backtracking search algorithm in load frequency control of multi-area interconnected power system. Ain Shams Eng. J. 2018, 19, 257-276. [CrossRef]

8. Shabani, H.; Vahidi, B.; Ebrahimpour, M. A robust PID controller based on imperialist competitive algorithm for load-frequency control of power systems. ISA Trans. 2013, 52, 88-95. [CrossRef] [PubMed]

9. Raju, M.; Saikia, L.C.; Sinha, N. Automatic generation control of a multi-area system using ant lion optimizer algorithm based PID plus second order derivative controller. Int. J. Electr. Power Energy Syst. 2016, 80, 52-63. [CrossRef]

10. Guha, D.; Roy, P.K.; Banerjee, S. Study of differential search algorithm based automatic generation control of an interconnected thermal-thermal system with governor dead-band. Appl. Soft Comput. 2017, 52, 160-175. [CrossRef]

11. Dewangan, S.; Prakash, T.; Singh, V.P. Design and performance analysis of elephant herding optimization based controller for load frequency control in thermal interconnected power system. Optim. Control. Appl. Methods 2021, 42, 144-159. [CrossRef]

12. Chaine, S.; Tripathy, M.; Jain, D. Non dominated cuckoo search algorithm optimized controllers to improve the frequency regulation characteristics of wind thermal power system. Eng. Sci. Technol. Int. J. 2017, 20, 1092-1105. [CrossRef]

13. Abid-Elazim, S.M.; Ali, E.S. Load frequency controller design of a two-area system composing of PV grid and thermal generator via firefly algorithm. Neural Comput. Appl. 2018, 30, 607-616. [CrossRef]

14. Guha, D.; Roy, P.K.; Banerjee, S. Whale optimization algorithm applied to load frequency control of a mixed power system considering nonlinearities and PLL dynamics. Energy Syst. 2020, 11, 699-728. [CrossRef]

15. Kalyan, C.N.S.; Rao, G.S. Coordinated control strategy for simultaneous frequency and voltage stabilization of the multi-area interconnected system considering communication time delays. Int. J. Ambient Energy 2021, 1-13. [CrossRef]

16. Nosratabadi, S.M.; Bornapour, M.; Gharaei, M.A. Grasshopper optimization algorithm for optimal load frequency control considering predictive function al modified PID controller in restructured multi-resource multi-area power system with redox flow battery units. Control. Eng. Pract. 2019, 89, 204-227. [CrossRef] 
17. Sobhanam, A.P.; Mary, P.M.; Mariasiluvairaj, W.I.; Wilson, R.D. Automatic generation control using an improved artificial electric field in multi-area power system. IETE J. Res. 2021, 1-13. [CrossRef]

18. Sahu, R.K.; Panda, S.; Padhan, S. A hybrid firefly algorithm and pattern search technique for automatic generation control of multi area power systems. Int. J. Electr. Power Energy Syst. 2015, 64, 9-23. [CrossRef]

19. Kalyan, C.N.S.; Rao, G.S. Combined frequency and voltage stabilization of multi-area multisource system by DE-AEFA optimized PID controller with coordinated performance of IPFC and RFBs. Int. J. Ambient Energy 2020, 1-17. [CrossRef]

20. Sharma, J.; Hote, Y.V.; Prasad, R. Robust PID load frequency controller design with specific gain and phase margin for multi-area power systems. IFAC-Pap. 2018, 51, 627-632. [CrossRef]

21. Tasnin, W.; Saikia, L.C. Comparative performance of different energy storage devices in AGC of multi-source system including geothermal power plant. J. Renew. Sustain. Energy 2018, 10, 024101. [CrossRef]

22. Arya, Y. automatic generation control of two-area electrical power systems via optimal fuzzy classical controller. J. Frankl. Inst. 2018, 355, 2662-2688. [CrossRef]

23. Arya, Y.; Kumar, N. Design and analysis of BFOA-optimized fuzzy PI/PID controller for AGC of multi-area traditional/restructured electrical power systems. Soft Comput. 2017, 21, 6435-6452. [CrossRef]

24. Sahu, R.K.; Panda, S.; Yegireddy, N.K. A novel hybrid DEPS optimized fuzzy PI/PID controller for load frequency control of multi-area interconnected power systems. J. Control Process 2014, 24, 1596-1608. [CrossRef]

25. Sahu, P.C.; Prusty, R.C.; Panda, S. Approaching hybridized GWO-SCA based type-II fuzzy controller in AGC of diverse energy source multi area power system. J. King Saud Univ.-Eng. Sci. 2020, 32, 186-197. [CrossRef]

26. Sahoo, D.K.; Sahu, R.K.; Sekhar, G.T.; Panda, S. A novel modified differential evolution algorithm optimized fuzzy proportional integral derivative controller for load frequency control with Thyristor controlled series compensator. J. Electr. Syst. Inf. Technol. 2018, 5, 944-963. [CrossRef]

27. Pradhan, P.C.; Sahu, R.K.; Panda, S. Firefly algorithm optimized fuzzy PID controller for AGC of multi-area multi-source power systems with UPFC and SMES. Eng. Sci. Technol. Int. J. 2016, 19, 338-354. [CrossRef]

28. Nayak, J.R.; Shaw, B.; Sahu, B.K. Application of adaptive-SOS (ASOS) algorithm based interval type-2 fuzzy-PID controller with derivative filter for automatic generation control of an interconnected power system. Eng. Sci. Technol. Int. J. 2018, 21, 465-485. [CrossRef]

29. Chen, X.; Li, Y.; Zhang, Y.; Ye, X.; Xiong, X.; Zhang, F. A novel hybrid model based on an improved seagull optimization algorithm for short-term wind speed forecasting. Processes 2021, 9, 387. [CrossRef]

30. Jain, M.; Rani, A.; Pachauri, N.; Singh, V.; Mittal, A.P. Design of fractional order 2-DOF PI controller for real-time control of heat flow experiment. Eng. Sci. Technol. Int. J. 2019, 22, 215-228. [CrossRef]

31. Kalyan, C.N.S.; Rao, G.S. Frequency and voltage stabilization in combined load frequency control and automatic voltage regulation of multi area system with hybrid generation utilities by AC/DC links. Int. J. Sustain. Energy 2020, 39, 1009-1029. [CrossRef]

32. Padhy, S.; Panda, S. A hybrid stochastic fractal search and pattern search technique based cascade PI-PD controller for automatic generation of multi-source power systems in presence of plug in electric vehicles. CAAI Trans. Intell. Technol. 2017, 2, 12-25. [CrossRef]

33. Rajesh, K.S.; Dash, S.S.; Rajagopal, R. Hybrid improved firefly-pattern search optimized fuzzy aided PID controller for automatic generation control of power systems with multi-type generations. Swarm Evol. Comput. 2019, 44, 200-211. [CrossRef]

34. Lal, D.K.; Barisal, A.K.; Tripathy, M. Load Frequency Control of Multi Source Multi-Area Nonlinear Power System with DE-PSO Optimized Fuzzy PID Controller in Coordination with SSSC and RFB. Int. J. Control. Autom. 2018, 11, 61-80. [CrossRef]

35. Gheisarnejad, M. An effective hybrid harmony search and cuckoo optimization algorithm based fuzzy PID controller for load frequency control. Appl. Soft Comput. 2018, 65, 121-138. [CrossRef]

36. Kouba, N.E.Y.; Menaa, M.; Hasni, M.; Boudour, M. A novel optimal combined fuzzy PID controller employing dragonfly algorithm for solving automatic generation control problem. Electr. Power Compon. Syst. 2018, 46, 2054-2070. [CrossRef]

37. Eskander, H.; Sadollah, A.; Bahreininejad, A.; Hamdi, M. Water cycle algorithm-A novel meta-heuristic optimization method for solving constrained engineering optimization problems. Comput. Struct. 2012, 110, 151-166. [CrossRef] 